This is the author's final, peer-reviewed manuscript as accepted for publication. The publisher-formatted version may be available through the publisher's web site or your institution's library.

\title{
Blockade of CB1 receptors prevents retention of extinction but does not increase low pre-incubated conditioned fear in the fear incubation procedure
}

Charles L. Pickens and Florence R. Theberge

\section{How to cite this manuscript}

If you make reference to this version of the manuscript, use the following information:

Pickens, C. L., \& Theberge, F. R. (2014). Blockade of CB1 receptors prevents retention of extinction but does not increase low pre-incubated conditioned fear in the fear incubation procedure. Retrieved from http://krex.ksu.edu

\section{Published Version Information}

Citation: Pickens, C. L., \& Theberge, F. R. (2014). Blockade of CB1 receptors prevents retention of extinction but does not increase low preincubated conditioned fear in the fear incubation procedure. Behavioural Pharmacology, 25(1), 23-31.

Copyright: @ 2014 Wolters Kluwer Health | Lippincott Williams \& Wilkins

Digital Object Identifier (DOI): doi:10.1097/FBP.0000000000000020

\section{Publisher's Link:}

http://journals.Iww.com/behaviouralpharm/Abstract/2014/02000/Blockade_of_CB1_rece ptors_prevents_retention_of.4.aspx 
October 16, 2013

Running head: CB1 fear incubation

Blockade of $\mathrm{CB} 1$ receptors prevents retention of extinction but does not increase low pre-incubated conditioned fear in the fear incubation procedure

Charles L. Pickens and Florence R. Theberge

Behavioral Neuroscience Branch, IRP/NIDA/NIH/DHHS, Baltimore, Maryland

Abbreviated Title: CB1 fear incubation

Text: 6652 words (including figure legends and references)

Abstract: 199 words

References: 45

Figures: 3

Tables: 1

Corresponding author (current address):

Dr. Charles Pickens

469 Bluemont Hall

Department of Psychological Science

Kansas State University

Manhattan, KS 66506

Tel: 785-532-0613; Fax: 785-532-5401

E-mail: pickens@ksu.edu

Acknowledgments: This research was supported by the Intramural Research Program of the NIDA, NIH. We thank Ozge Gunduz-Cinar and Yavin Shaham for helpful comments on this manuscript. The authors declare that they do not have any conflicts of interest (financial or otherwise) related to the data presented in this manuscript. 


\section{Abstract}

We recently developed a procedure to study fear incubation in which rats given 100 toneshock pairings over 10 days show low fear 2 days after conditioned fear training and high fear after 30 days. Notably, fear 2 days after 10 sessions of fear conditioning is lower than fear seen 2 days after a single session of fear conditioning, suggesting that fear is suppressed. Here, we investigate the potential role of $\mathrm{CB} 1$ receptor activation by endocannabinoids in this fear suppression. We gave rats 10 days of fear conditioning and then gave systemic injections of the CB1 receptor antagonist SR141716 before a conditioned fear test conducted 2 days later under extinction conditions. A second test was conducted without any injections on the following day (3 days post-training) to examine fear extinction retention. SR141716 injections did not increase fear expression 2 days after extended fear conditioning or affect within-session extinction, but impaired retention of between-session fear extinction in the day 3 test. These data suggest that CB1 receptor activation is not suppressing fear soon after extended fear conditioning in the fear incubation task. The data also add to an existing literature on the effects of CB1 receptors in extinction of conditioned fear.

Keywords: Fear incubation, fear conditioning, PTSD, CB1, endocannabinoids, rimonabant 
Fear conditioning involves pairing an initially neutral cue (e.g. a tone or distinctive place) with an aversive stimulus (e.g. footshock). After this training, the cue gains the ability to elicit an aversive reaction. In some cases, fear increases after the cessation of fear conditioning across an interval free of further stress or fear conditioning trials, a phenomenon called "fear incubation" (McAllister \& McAllister, 1967) [footnote 1]. There are reports of increases in fear expression across the 24-h following fear training in both humans and laboratory animals (Diven, 1937; Golin, 1961; McMichael, 1966; Houston et al., 1999; Balogh et al., 2002). However, in most cases, there are no changes in fear over days or weeks after the first 24-h period (Gleitman \& Holmes, 1967; Hendersen, 1978; Gale et al., 2004). Due to the difficulty in reliably observing a growth of fear over time beyond the first 24-h after fear conditioning, the mechanisms of fear incubation are not well understood.

We recently developed a model in which fear, as measured with conditioned suppression of leverpressing and conditioned freezing, is low 2 days after extended fear conditioning (10 sessions of tonefootshock pairings) and increased significantly 1 month after the end of conditioning (Pickens et al., 2009b; Pickens et al., 2010; Pickens et al., 2013). If only one day of fear conditioning was given, conditioned fear was high 2 days later and did not increase further across the subsequent month (Pickens et al., 2009b). In our initial pharmacological investigation, we studied the role of neuropeptide Y (NPY), an anxiolytic neuropeptide involved in anxiety and stress responses (Heilig et al., 1994), in fear incubation. We found that ventricular injections of neuropeptide $Y$ (NPY) reduced both incubated fear (10 days of fear training, test after 1 month) and non-incubated fear ( 1 day of fear training, test after 2 days) (Pickens et al., 2009a). However blockade of the $\mathrm{Y} 1$ receptor involved in the anxiolytic effects of NPY did not increase the low pre-incubated fear seen 2 days after extended (10 day) fear conditioning, suggesting that endogenous NPY neurotransmission is not responsible for the low fear seen soon after extended training.

Here, we examine whether endogenous cannabinoid neurotransmission is responsible for the low pre-incubated fear observed 2 days after extended fear conditioning, or has an effect on extinction of this low pre-incubated fear. Moderate levels of CB1 activation have anti-anxiety 
effects (Viveros et al., 2005; Ruehle et al., 2012). Also, CB1 receptor antagonist injections block within-session extinction in mice (Marsicano et al., 2002; Plendl \& Wotjak, 2010) and betweensession extinction retention in mice and rats (Marsicano et al., 2002; Chhatwal et al., 2005). CB1 knockout mice are impaired at within-session extinction (Marsicano et al., 2002; Cannich et al., 2004; Kamprath et al., 2006; Kamprath et al., 2009; Plendl \& Wotjak, 2010; Kamprath et al., 2011) and between session-extinction retention (Marsicano et al., 2002; Cannich et al., 2004; Kamprath et al., 2011). Because there were already several experiments that showed effects of SR141716 on the extinction of fear following limited fear conditioning (1-2 sessions), we wanted to investigate the effects of SR141716 on conditioned fear after extended fear conditioning. The fear incubation procedure, with its low pre-incubated fear that is not seen after other fear conditioning procedures, provides a novel opportunity to investigate the effects of CB1 receptors. This approach can investigate whether endocannabinoids acting at CB1 receptors cause a suppression of fear expression (as seen in the low preincubated fear test), in addition to the within- and between-session extinction that is often measured using other procedures. We gave rats 10 days of fear conditioning and 2 days later tested whether injections of the CB1 receptor antagonist/inverse agonist SR141716 (rimonabant) would increase low pre-incubated conditioned fear or slow within-session extinction. We also tested the rats the following day (day 3) without pre-test injections to see if SR141716 would affect between-session extinction retention.

\section{Methods}

All procedures followed the guidelines outlined in the "Principles of Laboratory Animal Care" (NIH publication no. 85-23) and were approved by the local Animal Care and Use Committee. Male Long-Evans rats (total $\mathrm{n}=31$, Charles River, Raleigh, NC, 295-370 g on the first day of food restriction) were individually housed in a colony room under a reverse 12-h:12-h light-dark cycle with lights off at 9 am. The rats were weighed and then given $4 \mathrm{~g} / \mathrm{d}$ of food until they reached $85 \%$ of their weight on day 1 , and then received $18-20 \mathrm{~g} / \mathrm{d}$ thereafter. The fear 
incubation effect is most apparent under food-restriction. Fear incubation is seen at food-restriction conditions both milder and more severe than the ones used in this experiment, and is not dependent on the particular food restriction conditions. However, the strongest incubation effect was seen under the conditions used here where the rats are restricted to $85 \%$ of their initial weights and then allowed to grow (Pickens et al., 2009b; Pickens et al., 2010). Experiments were conducted in 12 self-administration chambers (Med Associates, St Albans, VT). Each chamber had two levers $9 \mathrm{~cm}$ above the floor, but only one lever ("active," retractable lever) activated the pellet dispenser, delivering 45mg food pellets (\# F00021, 5.5\% fat, 60\% carbohydrate, 4.5\% fiber; Bioserv, Frenchtown, NJ). The chambers' grid floors were connected to electric shock generators.

\section{Drugs}

SR141716 ([N-(piperidin-1-yl)-5-(4-chlorophenyl)-1-(2,4-dichlorophenyl)-4-methyl-1 Hpyrazole-3-carboxamide) (NIMH Chemical Synthesis and Drug Supply Program) was prepared fresh before testing. SR141716 was dissolved in 5\% ethanol and 5\% Tween-80 in sterile water and was injected (0,1 and $3 \mathrm{mg} / \mathrm{kg}$, s.c.) $30 \mathrm{~min}$ before testing. Doses were chosen based on previous studies showing effects on reinstatement of alcohol, nicotine and oral-sucrose seeking (Cippitelli et al., 2005; De Vries et al., 2005) in rats.

\section{Procedures}

We used a fear incubation protocol consisting of 7 phases (Fig. 1A): magazine training ( 1 session), lever press training (5 sessions), conditioned fear training (10 sessions), incubation period ( 2 days or 30 days), lever reacquisition ( 1 session), cue-induced fear test (1 session), and extinction test (1 session). Rats were trained during the dark cycle. Sessions began with extension of the active lever and illumination of a red houselight. Rats were weighed and fed after the daily sessions.

\section{$\underline{\text { Food/lever training }}$}

Eight-nine days after the initial day of food restriction, the rats were given 60-min magazine training (pellet delivery every $125 \mathrm{~s}$ ). The following day, 2 sessions on a fixed- 
interval-1 (FI-1) reinforcement schedule (lever-presses could earn a pellet each sec) were run 2$4 \mathrm{~h}$ apart. These sessions ended when rats received 50 pellets (up to $1 \mathrm{~h}$ ). The rats were then given one 90-min session in which pellets were earned under a variable-interval-30 (VI-30) reinforcement schedule (pellet availability for lever-presses ranging from 1 to $59 \mathrm{sec}$ ), and 2 daily 90-min sessions on a VI-60 schedule (pellet availability ranging from 1 to $119 \mathrm{sec}$ ). Rats were maintained on the $\mathrm{VI}-60$ schedule for the rest of the experiment.

\section{Conditioned fear training}

Conditioned fear training occurred over ten 90 -min sessions during which the rats were given ten 30 -sec tones $(2900 \mathrm{~Hz}, 20 \mathrm{~dB}$ above background), ranging from 3 to 14 min apart and co-terminating with an electric shock (0.5-sec, $0.5-\mathrm{mA}$, scrambled, shock intensity adjusted for inter-chamber variability) while earning pellets on a VI-60 schedule. Conditioned inhibition of lever-pressing for food pellets was our measure of fear (Estes \& Skinner, 1941; Hunt \& Brady, 1951). Lever-presses were recorded during the 30-sec prior to tone presentation (Precue) and during the 30-sec tone presentation (Cue), and were converted into a suppression ratio: Suppression ratio $=(($ Precue-Cue $) /($ Precue + Cue $))$. The suppression ratio normalizes leverpressing during the tone for baseline precue responding (Annau \& Kamin, 1961; Armony et al., 1997). A value of 1 indicates total conditioned suppression of lever-pressing during tone presentation (high fear). A value of 0 reflects no lever-press suppression during tone presentation (no fear). The rats assigned to the different treatments (Incubation Day and Dose) were matched for their precue lever press rates and suppression ratios during training.

\section{Cue-induced fear and extinction retention tests}

Two days after conditioned fear training, we determined the effects of acute injections of the $\mathrm{CB} 1$ receptor antagonist, SR141716 prior to cue-induced fear tests. Rats were divided into 3 groups ( $\mathrm{n}=7-8 / \mathrm{group}$ ) that received either vehicle or SR141716 (1 or $3 \mathrm{mg} / \mathrm{kg}$, s.c.). 
One day after the conditioned fear training phase, lever-pressing was re-stabilized in a 90-min baseline session with no tones or shocks during the lever reacquisition phase. The following day (day 2 post-training), conditioned fear to the tone was tested by presenting four 30-sec tones, without shock, over $35 \mathrm{~min}$. The first tone occurred after $6.5 \mathrm{~min}$ and subsequent tones occurred after inter-trial intervals of 4,7 , and $11 \mathrm{~min}$. Rats received injections of vehicle or SR141716 (1 or $3 \mathrm{mg} / \mathrm{kg}$, s.c) $30 \mathrm{~min}$ before the start of the test session. On the following day (day 3 post-training), the rats received a second conditioned fear test without any prior injections, to test for retention of conditioned fear extinction. The injections before the day 2 test were intended to allow for a test of the effects of SR141716 on retrieval and expression of the fear memory and within-session extinction on day 2. There were no injections before the day 3 retest, to allow for an examination of how SR141716 affected extinction learning or consolidation the previous day without any effect of SR141716 on fear expression or retrieval during this test. We assessed both conditioned suppression and conditioned freezing during the initial cued fear test (Test) and extinction retention test (Retest). Multiple measures were used in order to ensure that any pattern of data seen was not dependent upon the use of a single fear measure. Freezing, defined as immobility except for movement related to breathing (Fanselow, 1980), was measured during the precue and cue periods every $2 \mathrm{sec}$ (according to a metronome) by a blind rater previously shown to have interrater reliability of $r=0.92$ with another blind rater. The suppression ratios and conditioned freezing across the 4 extinction trials were used as our measure of conditioned fear in order to assess the strength of the incubated fear response over repeated trials.

An additional group of rats $(n=9)$ was tested for conditioned fear 30-31 days after fear conditioning training. These rats were weighed and fed daily during the incubation interval, with continuation of the food-restriction conditions. The experimental test conditions were the same as the ones described above with a lever reacquisition session occurring on day 29 posttraining, and two cue-induced fear tests occurring on day 30 and day 31 post-training, respectively. On the initial conditioned fear test, rats received vehicle injections 30 min before 
the start of the test session on day 30. The aim of this experimental group was to verify that, under our experimental conditions, the fear levels measured on day 2 and 3 post-training were lower (low pre-incubated fear) compared to the ones measure at a 1 month incubation interval.

\section{Statistical analyses}

All data were analyzed using Statistica 5.1 software (Tulsa, OK, USA). Conditioned fear training was analyzed for the conditioned suppression measure, to ensure that all groups were equated before testing. These conditioned fear training data were analyzed with a mixed-factor ANOVA for the course of training, with Group (4 levels: Day 2 Test-Vehicle, Day 2-1 mg/kg, Day 2 Test-3 mg/kg, or Day 30-Vehicle) as the between-subjects factor and Training Session (the 10 fear conditioning days) as the within-subjects factor. The conditioned fear training data were also analyzed with a between-subjects factor ANOVA for the last day of training, with Group (4 levels: Day 2 Test-Vehicle, Day 2-1 mg/kg, Day 2 Test-3 mg/kg, Day 30-Vehicle) as the between-subjects factor.

Conditioned fear test data were analyzed separately for the conditioned suppression and conditioned freezing measures. For each measure, conditioned fear was compared in the Day 2 Test-Vehicle and Day 30 Test-Vehicle groups to verify that fear on day 2-3 was at low preincubation levels compared to fear that increased across 1 month. These data were analyzed with a mixed factor ANOVA with Incubation Day (Day 2-3 or Day 30-31) as the betweensubjects factor and Test/Retest Day (Fear Expression Test or Extinction Retention) and Test Trial (the 4 test trials per day) as the within-subjects factors. For each measure, conditioned fear was also compared across the 3 doses of SR141716 $(0,1$, and $3 \mathrm{mg} / \mathrm{kg})$ in the groups tested on Day 2-3 to determine the effect of CB1 receptor blockade on low pre-incubated fear. These data were analyzed with a mixed factor ANOVA with SR141716 Dose $(0,1$ or $3 \mathrm{mg} / \mathrm{kg})$ as the between-subjects factor and Test/Retest Day (Fear Expression Test or Extinction Retention) and Test Trial (the 4 test trials per day) as the between-subjects factors. Significant effects $(P<0.05)$ in the different ANOVAs were followed by post-hoc Tukey HSD tests. 


\section{Results}

\section{Lever-press and Conditioned fear training}

Lever-press training led to a high rate of responding before the start of conditioned fear training

(Figure 1B). Conditioned suppression increased from the first day of fear training but, in contrast to many of our earlier studies, did not decrease as training progressed (Fig. 1C). This replicates an earlier finding that conditioned fear does not decrease across training at these feeding conditions (restriction to $85 \%$ of original body weight followed by $18-20 \mathrm{~g}$ of food per day (Pickens et al., 2010)). An ANOVA of the suppression ratios during training showed a significant effect of Training Session $\left(F_{(9,243)}=3.1, p<0.01\right)$. The groups were balanced such that there were no effects or interactions with Group (all $F<1$ ) across the 10 sessions of conditioning or during the last conditioning session.

Conditioned fear testing

As previously shown (Pickens et al., 2010), conditioned fear (as measured by conditioned suppression of lever pressing and conditioned freezing) increased from 2 days to 1 month after extended fear conditioning. Systemic injections of SR141716 had no effect on fear expression or within-session extinction during the day 2 fear test. The lower dose of SR141716 tested $(1 \mathrm{mg} / \mathrm{kg}$ ) prevented the decrease in fear expression on the following test day (betweensession extinction retention) on day 3 .

Statistical analyses of each fear measure demonstrated the fear incubation effect. Conditioned suppression in rats given vehicle injections was higher on day 30-31 than on days 2-3 (Fig. 2A). An ANOVA of conditioned suppression in the vehicle groups, with the factors of Incubation Day (Day 2-3 or Day 30-31), Test/Retest Day (Fear Expression Test or Extinction Retention) and Test Trial (the 4 test trials per day) showed significant effects of Incubation Day $\left(F_{(1,14)}=5.4, p<0.05\right)$, Test/Retest Day $\left(F_{(1,14)}=34.4, p<0.01\right)$ and Test Trial $\left(F_{(3,42)}=15.9, p<0.01\right)$ and a significant interaction of Test/Retest Day $X$ Test Trial $\left(F_{(3,42)}=3.6, p<0.05\right)$. No other 
interactions were significant $(a l l ~ F<1)$. Conditioned freezing in rats given vehicle injections was also higher on day 30-31 than on days 2-3 (Fig. 2B). An ANOVA of the conditioned freezing in the vehicle groups, with the factors of Incubation Day (Day 2-3 or Day 30-31), Test/Retest Day (Fear Expression Test or Extinction Retention) and Test Trial (the 4 test trials per day) showed significant effects of Incubation Day $\left(F_{(1,14)}=5.3, p<0.05\right)$, Test/Retest Day $\left(F_{(1,14)}=12.3, p<0.01\right)$ and Test Trial $\left(F_{(3,42)}=7.9, p<0.01\right)$. No other interaction were significant (all $\left.p>0.05\right)$.

The lower dose of SR141716 $(1 \mathrm{mg} / \mathrm{kg})$ blocked the retention of extinction of conditioned suppression at 2-3 days after extended fear training, but neither $1 \mathrm{mg} / \mathrm{kg}$ nor $3 \mathrm{mg} / \mathrm{kg}$ SR141716 had an effect on fear expression at this time (Fig. 3A). An ANOVA of conditioned suppression during the cue with the factors of SR141716 Dose (0,1 or $3 \mathrm{mg} / \mathrm{kg}$ ), Test/Retest Day (Fear Expression Test or Extinction Retention) and Test Trial (the 4 test trials per day) revealed significant effects of Test/Retest Day $\left(F_{(1,19)}=21.7, p<0.01\right)$, Test Trial $\left(F_{(3,57)}=16.2, p<0.01\right)$ and significant interactions of SR141716 Dose X Test/Retest Day $\left(F_{(2,19)}=3.7, p<0.05\right)$ and Test/Retest Day $X$ Test Trial $\left(F_{(3,57)}=5.3, p<0.01\right)$. No other main effects or interactions were significant (all $F<1)$. The significant SR141716 Dose X Test/Retest Day interaction was followed up by post-hoc Tukey HSD tests. This analysis demonstrated that there were no differences between the groups given the different SR141716 doses in the day 2 fear test, but that the group treated with $1 \mathrm{mg} / \mathrm{kg}$ of SR141716 exhibited significantly higher conditioned suppression than the vehicle group in the extinction retention test the following day. Precue lever press rates in the three groups are shown in Table 1. An ANOVA of precue lever pressing with the factors of SR141716 Dose (0,1 or $3 \mathrm{mg} / \mathrm{kg}$ ), Test/Retest Day (Fear Expression Test or Extinction Retention) and Test Trial (the 4 test trials per day) showed a significant effect of Test Trial $\left(F_{(3,57)}=5.4, p<0.01\right)$. No other effects or interactions were significant $(a l l ~ F<1)$.

The lower dose of SR141716 blocked the retention of extinction of conditioned freezing at 2-3 days after extended fear training, but neither SR141716 dose tested ( $1 \mathrm{and} 3 \mathrm{mg} / \mathrm{kg}$ ) had an effect on fear expression at this time (Fig. 3B). An ANOVA of conditioned freezing during 
the cue with the factors of SR141716 Dose $(0,1$ or $3 \mathrm{mg} / \mathrm{kg})$, Test/Retest Day (Fear Expression Test or Extinction Retention) and Test Trial (the 4 test trials per day) revealed significant effects of Test/Retest Day $\left(F_{(1,19)}=12.0, p<0.01\right)$, Test Trial $\left(F_{(3,57)}=13.9, p<0.01\right)$ and a significant interaction of SR141716 Dose X Test/Retest Day $\left(F_{(2,19)}=3.6, p<0.05\right)$. No other main effects or interactions were significant (all p>0.05). The significant SR141716 Dose X Test/Retest Day interaction was followed up by Tukey HSD tests. This analysis demonstrated that there were no differences between the groups given the different SR141716 doses in the fear test, but that the group treated with $1 \mathrm{mg} / \mathrm{kg}$ of SR141716 exhibited significantly higher conditioned freezing than the vehicle group in the extinction retention test the following day. Precue conditioned freezing in the three groups is shown in Table 1. An ANOVA of precue freezing with the factors of SR141716 Dose (0, 1 or 3 mg/kg), Test/Retest Day (Fear Expression Test or Extinction Retention) and Test Trial (the 4 test trials per day) revealed no significant effects or interactions (all $p>0.05$ ).

\section{Discussion}

We found that the fear response, as measured by conditioned suppression of lever pressing and conditioned freezing during exposure to a discrete tone cue previously paired with shock, was higher 1 month after 10 sessions of fear training than after 2 days. These findings replicate those from our recent studies (Pickens et al., 2009a; Pickens et al., 2009b; Pickens et al., 2010) that demonstrated that conditioned fear following an extended training period incubates over time (also see Millenson \& Dent (1971) and Rosas \& Alonso (1997) for related findings). Because previous findings demonstrated that fear is lower 2 days after extended fear training (10 sessions) than 2 days after limited fear conditioning ( 1 session), this procedure provides an opportunity to determine whether endocannabinoids acting at CB1 receptors can suppress fear in the absence of extinction, which is not possible with the high fear seen soon after limited fear conditioning. We investigated whether endocannabinoids acting at CB1 receptors are suppressing the fear 
response 2 days after extended fear conditioning. We found no evidence that blocking CB1 receptors "unmasks" suppressed fear expression 2 days after extended fear conditioning. We also found no evidence that blocking CB1 receptors prevents within-session fear extinction measured two days post-training, although the lower dose of the CB1 receptor antagonist (1 $\mathrm{mg} / \mathrm{kg}$, s.c.) did impair between-session retention of the extinction assessed on the following day (day 3 post-training). Notably, these effects were not limited to a single fear measure, as this pattern of data was consistent between two measures of conditioned fear (conditioned freezing and conditioned suppression of lever pressing).

$\underline{\text { Technical considerations }}$

There are several methodological issues that should be considered before concluding that $\mathrm{CB1}$ receptor blockade impaired retention of extinction. These methodological considerations include 1) the effects that SR141716 systemic administration may have on locomotor activity or motivation to respond for food, 2) the possibility that SR141716 was still present during the day 3 test, and 3) the possible causes for the higher dose of SR141716 tested ( $3 \mathrm{mg} / \mathrm{kg}$, s.c.) being ineffective at affecting the fear response under our experimental conditions.

One important factor to consider is whether SR141716 may have caused changes in baseline locomotor activity or in motivation to earn food by lever pressing, since conditioned suppression of lever pressing would be affected by changes in baseline lever pressing. Although previous studies have found that SR141716 does not affect locomotor activity in the 1$5 \mathrm{mg} / \mathrm{kg}$ i.p. range (Freedland et al., 2000; McLaughlin et al., 2003), SR141716 can affect lever pressing for food under fixed-ratio schedules at these doses (Freedland et al., 2000; McLaughlin et al., 2003; De Vry \& Jentzsch, 2004). However, as can be seen in Table 1, there were no significant changes in baseline lever-press rates or precue freezing in the tests. Therefore, it is highly unlikely that SR141716-induced changes in locomotor activity or SR141716-induced changes in motivation for the food caused by food-restriction are responsible for the changes in conditioned 
freezing or conditioned suppression of lever-pressing seen in this experiment. In addition, because lever-presses in our task earned food pellets, the fact that we saw the same pattern of results in our lever-press-dependent and lever-press-independent fear measures (conditioned suppression of lever pressing and conditioned freezing, respectively) suggests that changes in the motivation for food are not responsible for the effects of SR141716 in our task.

A second issue that should be addressed is whether the impairment of extinction retention seen on day 3 test after injections of SR14716 (1 mg/kg, s.c.) prior day 2 test, is due to some effects on extinction learning or consolidation, or whether some residual SR1419716 still present on day 3 may interfere with the fear response on that day. Effects of residual SR141716 on behavior in the day 3 test seem unlikely for several reasons. First, experiments examining the effects of SR141716 on antagonizing the behavioral effects of $\Delta^{9}$-THC on drug discrimination and lever pressing for food have estimated its functional half-life to be between $\sim 100$ and 130 minutes depending on the $\Delta^{9}$-THC dose (Jarbe et al., 2010). Furthermore, an experiment looking at the effects of SR141716 on lever-pressing for food in the absence of $\Delta^{9}$ THC estimated its half-life to be $\sim 15$ hours (McLaughlin et al., 2003). In both cases, the SR141716 half-life is less than the 24.5 hour interval between the SR141716 injection and the day 3 test. Second, the SR141716 injection had no effect on fear expression or within-session extinction in the day 2 test. Thus, it is unlikely that the effects of SR141716 in the day 3 test were caused by residual SR141716 acutely affecting fear expression, retrieval of the fear memory, or within-session extinction during the day 3 test.

The effect of the $1 \mathrm{mg} / \mathrm{kg}$, but not the $3 \mathrm{mg} / \mathrm{kg}$ dose in our study was surprising. However, it is possible that the higher $3 \mathrm{mg} / \mathrm{kg}$ dose tested may have caused off-target effects (Pertwee et al., 2010). These potential effects may be explained by a higher bioavailability of SR141716 due to the subcutaneous route of administration or the potential decreased uptake into adipose tissue of the highly lipophilic SR141716 (Katoch-Rouse et al., 2003) in food restricted animals with lower body fat. 
No unmasking of fear by blocking CB1 receptors

In previous studies, we have shown that a single session of fear conditioning, using the same parameters as in the extended fear training used to demonstrate fear incubation, causes high fear in a test 2 days later (Pickens et al., 2009a; Pickens et al., 2009b). However, after extended fear conditioning, fear is relatively low. This is in accord with previous literature that showed that, with relatively mild footshock parameters ( $0.5 \mathrm{~mA}$, but not stronger), there is a non-monotonic fear acquisition curve such that extended training causes lower fear expression than limited training (Annau \& Kamin, 1961; Millenson \& Hendry, 1967). It seems likely that fear is suppressed 2 days after extended fear training, although the neurobiological basis of this suppression of fear is unknown. We previously showed that the NPY Y1 antagonist BIBO 3304 did not increase low pre-incubated fear (Pickens et al., 2009a), suggesting that changes in NPY signaling are not responsible for the low fear 2 days after extended fear training. Another promising candidate was the endocannabinoids, since moderate levels of CB1 activation have anti-anxiety effects (Viveros et al., 2005; Ruehle et al., 2012) and can improve extinction retention (Gunduz-Cinar et al., 2012). The present experiment tested whether endocannabinoids, acting at the CB1 receptor, are suppressing fear. However, blockade of the CB1 receptors had no effect on fear expression on day 2 as assayed using two different measures of conditioned fear, suggesting that CB1 activity is not suppressing fear prior to fear incubation under these experimental conditions. $\underline{\text { CB1 blockade prevents between-session, not within-session, extinction }}$

We found evidence for an effect of CB1 receptor blockade on between-session extinction, but not on within-session extinction. The effect on between-session extinction retention is in line with findings from other laboratories, in which CB1 receptor blockade using SR141716 before extinction sessions after limited fear conditioning (1-2 sessions) causes an impairment of fear extinction retention 24 hours later (Marsicano et al., 2002; Chhatwal et al., 2005) (but see (Plendl \& Wotjak, 2010)). However, several other studies have also demonstrated an effect of CB1 receptor antagonist or CB1 receptor genetic knockout on within-session extinction as well 
(Marsicano et al., 2002; Cannich et al., 2004; Kamprath et al., 2006; Kamprath et al., 2009; Plendl \& Wotjak, 2010; Kamprath et al., 2011).

There are several potential reasons why we did not find an effect of CB1 blockade on within-session extinction. It appears that effects of CB1 receptor antagonism on within- and between- session extinction are dissociable, depending on the brain site affected. Injections of the CB1 receptor antagonist AM251 into the central amygdala impaired within-session extinction, but not between-session extinction, while injections of AM251 into the basolateral amygdala impaired between-session extinction retention, but not within-session extinction (Kamprath et al., 2011). Thus, our systemic injections may have had a greater effect on the basolateral amygdala than the central amygdala.

Alternatively, our experiment had several methodological differences from previous experiments where CB1 blockade or knockout impaired within-session extinction, including differences in species, feeding conditions, and the particular method of measuring fear or shock intensity used in fear conditioning. Previous experiments that have demonstrated impairments in within-session extinction have investigated free-fed mice with no concurrent operant task (Marsicano et al., 2002; Cannich et al., 2004; Kamprath et al., 2006; Kamprath et al., 2009; Plendl \& Wotjak, 2010; Kamprath et al., 2011). In contrast, we investigated food-restricted rats performing a concurrent lever-press task, which could more closely resemble the human condition where people maintain relatively stable weights over time and there are goals and tasks to be accomplished that compete with aversive emotional reactions for control of behavior. Thus, either species differences, task differences, or differences in feeding conditions could account for the different effects of a CB1 receptor antagonist on fear extinction. Notably, food restriction can affect the levels of endocannabinoids and CB1 receptors (Hanus et al., 2003; Bello et al., 2012), and this may change the effects of a CB1 receptor antagonist at the CB1 receptor. It is unclear which feeding conditions more closely resemble the human condition, although it is possible that the normal function of 
CB1 receptors in humans maintaining stable body weights more closely resembles that seen in our food restricted rats.

However, the particular shock intensity and/or the long ITls between the extinction trials may also account for the lack of an effect of the CB1 receptor antagonist on within-session extinction. A previous experiment in mice found that CB1 knockout mice were impaired in extinction of fear conditioning using 0.7 - or $1.5-\mathrm{mA}$ shocks, but not after conditioning using 0.5 mA shocks or those at the mouse's pain threshold (Kamprath et al., 2009). Our experiment used $0.5-\mathrm{mA}$ shocks in rats whose electrical resistance is higher. In contrast, previous experiments demonstrating an effect of $\mathrm{CB} 1$ receptor blockade on within-session extinction used 0.7-mA or higher shock intensity in mice with a lower electrical resistance (Marsicano et al., 2002; Cannich et al., 2004; Kamprath et al., 2006; Kamprath et al., 2009; Plendl \& Wotjak, 2010; Kamprath et al., 2011). Likewise, the previous experiments demonstrating impaired within-session extinction all used either a single $180-200-s e c$ tone for extinction or individual tones with an average ITI of 80 sec (Marsicano et al., 2002; Cannich et al., 2004; Kamprath et al., 2006; Kamprath et al., 2009; Plendl \& Wotjak, 2010; Kamprath et al., 2011). In contrast, we gave individual trials during extinction and the average ITI between extinction trials in our test was 440 seconds. The effects of CB1 receptors in within-session extinction have been suggested to be due to their role in a habituation-like process (Kamprath et al., 2006). However, a non-associative habituation-like process has been suggested to play a larger role in withinsession extinction with massed extinction trials (shorter ITIs) (Delamater, 2004). Therefore, it is possible that CB1 receptors were not necessary for within-session extinction in our task because the longer ITls in our task cause extinction to occur through a process other than habituation.

Our results suggest that within- and between-session extinction are dissociable (as in Plendl \& Wotjak, 2010, although they find the opposite pattern of CB1 receptor involvement). Our findings also replicate previous findings from other laboratories that between-session extinction, which represents the long-term memory from the extinction manipulation, is disrupted by CB1 receptor blockade (Marsicano et al., 2002; Chhatwal et al., 2005). However, we failed to replicate findings from other laboratories that within- 
session extinction, which is often attributed to non-associative processes that occur during the nonreinforced presentations of the CS, is also impaired by CB1 receptor blockade (Marsicano et al., 2002; Cannich et al., 2004; Kamprath et al., 2006; Kamprath et al., 2009; Plendl \& Wotjak, 2010; Kamprath et al., 2011). It is unclear whether this is due to longer ITIs causing within-session extinction to proceed through different mechanisms that are CB1 receptor-independent, due to lower shock intensities causing a fear memory that does not require CB1 receptors for extinction, or some other methodological difference. $\underline{\text { Conclusions }}$

Although blockade of CB1 receptors with SR141716 prevented between-session extinction retention, we found no role for CB1 receptors in within-session extinction or in fear expression 2 days after extended fear conditioning. To the best of our knowledge, this is the first demonstration of $\mathrm{CB} 1$ receptor blockade impairing between-session extinction of fear measured with conditioned suppression of lever-pressing. These findings also suggest that endocannabinoids acting at the CB1 receptor are not suppressing fear and causing the low "pre-incubated" fear seen 2 days after extended fear conditioning. Further work will need to be conducted to investigate other neural systems involved in fear extinction, habituation, or anxiety responses to determine the mechanism causing the suppressed fear.

Footnote 1: The term fear incubation has also been used in reference to generalization of the fear to other cues that were never paired with shock (Siegmund \& Wotjak, 2007) or increases in conditioned responding that occur with non-reinforced presentations of the CS (Eysenck, 1968). We believe these represent different phenomena than the one we are studying. 


\section{$\underline{\text { References }}$}

Annau Z, Kamin LJ (1961). The conditioned emotional response as a function of intensity of the US. J Comp Physiol Psychol, 54 428-432.

Armony JL, Servan-Schreiber D, Romanski LM, Cohen JD, LeDoux JE (1997). Stimulus generalization of fear responses: effects of auditory cortex lesions in a computational model and in rats. Cereb Cortex, 7 157-165.

Balogh SA, Radcliffe RA, Logue SF, Wehner JM (2002). Contextual and cued fear conditioning in C57BL/6J and DBA/2J mice: context discrimination and the effects of retention interval. Behav Neurosci, 116 947-957.

Bello NT, Coughlin JW, Redgrave GW, Ladenheim EE, Moran TH, Guarda AS (2012). Dietary conditions and highly palatable food access alter rat cannabinoid receptor expression and binding density. Physiol Behav, 105 720-726.

Cannich A, Wotjak CT, Kamprath K, Hermann H, Lutz B, Marsicano G (2004). CB1 cannabinoid receptors modulate kinase and phosphatase activity during extinction of conditioned fear in mice. Learn Mem, 11 625-632.

Chhatwal JP, Davis M, Maguschak KA, Ressler KJ (2005). Enhancing cannabinoid neurotransmission augments the extinction of conditioned fear. Neuropsychopharmacology, 30 516-524.

Cippitelli A, Bilbao A, Hansson AC, del Arco I, Sommer W, Heilig M, Massi M, Bermudez-Silva FJ, Navarro M, Ciccocioppo R, de Fonseca FR (2005). Cannabinoid CB1 receptor antagonism reduces conditioned reinstatement of ethanol-seeking behavior in rats. Eur $J$ Neurosci, 21 2243-2251.

De Vries TJ, de Vries W, Janssen MC, Schoffelmeer AN (2005). Suppression of conditioned nicotine and sucrose seeking by the cannabinoid-1 receptor antagonist SR141716A. Behav Brain Res, 161 164-168.

De Vry J, Jentzsch KR (2004). Partial agonist-like profile of the cannabinoid receptor antagonist SR141716A in a food-reinforced operant paradigm. Behav Pharmacol, 15 13-20.

Delamater AR (2004). Experimental extinction in Pavlovian conditioning: behavioural and neuroscience perspectives. $Q J$ Exp Psychol B, 57 97-132.

Diven K (1937). Certain determinants in the conditioning of anxiety reactions. J Psychol Interdisciplinary and Applied, 3 291-308.

Estes WK, Skinner BF (1941). Some quantitative properties of anxiety. J Exp Psychol, 29390 400.

Eysenck HJ (1968). A theory of the incubation of anxiety-fear responses. Behav. Res. Ther., 6 309-321.

Fanselow MS (1980). Conditioned and unconditional components of post-shock freezing. Pavlov J Biol Sci, 15 177-182. 
Freedland CS, Poston JS, Porrino LJ (2000). Effects of SR141716A, a central cannabinoid receptor antagonist, on food-maintained responding. Pharmacol Biochem Behav, 67 265-270.

Gale GD, Anagnostaras SG, Godsil BP, Mitchell S, Nozawa T, Sage JR, Wiltgen B, Fanselow MS (2004). Role of the basolateral amygdala in the storage of fear memories across the adult lifetime of rats. J Neurosci, 24 3810-3815.

Gleitman H, Holmes PA (1967). Retention of incompletely learned CER in rats. Psychon Sci, 7 19-20.

Golin S (1961). Incubation effect: role of awareness in an immediate versus delayed test of conditioned emotionality. J Abnorm Soc Psychol, 63 534-539.

Gunduz-Cinar O, Macpherson KP, Cinar R, Gamble-George J, Sugden K, Williams B, Godlewski G, Ramikie TS, Gorka AX, Alapafuja SO, Nikas SP, Makriyannis A, Poulton R, Patel S, Hariri AR, Caspi A, Moffitt TE, Kunos G, Holmes A (2012). Convergent translational evidence of a role for anandamide in amygdala-mediated fear extinction, threat processing and stress-reactivity. Mol Psychiatry.

Hanus L, Avraham Y, Ben-Shushan D, Zolotarev O, Berry EM, Mechoulam R (2003). Short-term fasting and prolonged semistarvation have opposite effects on 2-AG levels in mouse brain. Brain Res, 983 144-151.

Heilig M, Koob GF, Ekman R, Britton KT (1994). Corticotropin-releasing factor and neuropeptide Y: role in emotional integration. Trends Neurosci, 17 80-85.

Hendersen RW (1978). Forgetting and conditioned fear inhibition. Learn Motiv, 9 16-30.

Houston FP, Stevenson GD, McNaughton BL, Barnes CA (1999). Effects of age on the generalization and incubation of memory in the F344 rat. Learn Mem, 6 111-119.

Hunt HF, Brady JV (1951). Some effects of electro-convulsive shock on a conditioned emotional response ("anxiety"). J Comp Physiol Psychol, 44 88-98.

Jarbe TU, Gifford RS, Makriyannis A (2010). Antagonism of (9)-THC induced behavioral effects by rimonabant: time course studies in rats. Eur J Pharmacol, 648 133-138.

Kamprath K, Marsicano G, Tang J, Monory K, Bisogno T, Di Marzo V, Lutz B, Wotjak CT (2006). Cannabinoid CB1 receptor mediates fear extinction via habituation-like processes. J Neurosci, 26 6677-6686.

Kamprath K, Plendl W, Marsicano G, Deussing JM, Wurst W, Lutz B, Wotjak CT (2009). Endocannabinoids mediate acute fear adaptation via glutamatergic neurons independently of corticotropin-releasing hormone signaling. Genes Brain Behav, 8 203211.

Kamprath K, Romo-Parra H, Haring M, Gaburro S, Doengi M, Lutz B, Pape HC (2011). Shortterm adaptation of conditioned fear responses through endocannabinoid signaling in the central amygdala. Neuropsychopharmacology, 36 652-663. 
Katoch-Rouse R, Pavlova OA, Caulder T, Hoffman AF, Mukhin AG, Horti AG (2003). Synthesis, structure-activity relationship, and evaluation of SR141716 analogues: development of central cannabinoid receptor ligands with lower lipophilicity. J Med Chem, 46 642-645.

Marsicano G, Wotjak CT, Azad SC, Bisogno T, Rammes G, Cascio MG, Hermann H, Tang J, Hofmann C, Zieglgansberger W, Di Marzo V, Lutz B (2002). The endogenous cannabinoid system controls extinction of aversive memories. Nature, 418 530-534.

McAllister DE, McAllister WR (1967). Incubation of fear: an examination of the concept. J Exp Res Personality, 2 180-190.

McLaughlin PJ, Winston K, Swezey L, Wisniecki A, Aberman J, Tardif DJ, Betz AJ, Ishiwari K, Makriyannis A, Salamone JD (2003). The cannabinoid CB1 antagonists SR 141716A and AM 251 suppress food intake and food-reinforced behavior in a variety of tasks in rats. Behav Pharmacol, 14 583-588.

McMichael JS (1966). Incubation of anxiety and instrumental behavior. J Comp Physiol Psychol, $61208-211$.

Millenson JR, Dent JG (1971). Habituation of conditioned suppression. Q J Exp Psychol, 23 126-134.

Millenson JR, Hendry DP (1967). Quantification of response suppression in conditioned anxiety training. Can J Psychol, 21 242-252.

Pertwee RG, Howlett AC, Abood ME, Alexander SP, Di Marzo V, Elphick MR, Greasley PJ, Hansen HS, Kunos G, Mackie K, Mechoulam R, Ross RA (2010). International Union of Basic and Clinical Pharmacology. LXXIX. Cannabinoid receptors and their ligands: beyond $\mathrm{CB}(1)$ and $\mathrm{CB}(2)$. Pharmacol Rev, 62 588-631.

Pickens CL, Adams-Deutsch T, Nair SG, Navarre BM, Heilig M, Shaham Y (2009a). Effect of pharmacological manipulations of neuropeptide $Y$ and corticotropin-releasing factor neurotransmission on incubation of conditioned fear. Neuroscience, 164 1398-1406.

Pickens CL, Golden SA, Adams-Deutsch T, Nair SG, Shaham Y (2009b). Long-lasting incubation of conditioned fear in rats. Biol Psychiatry, 65 881-886.

Pickens CL, Golden SA, Nair SG (2013). Incubation of fear. Curr Protoc Neurosci, Chapter 6 Unit 627.

Pickens CL, Navarre BM, Nair SG (2010). Incubation of conditioned fear in the conditioned suppression model in rats: role of food-restriction conditions, length of conditioned cue, and generality to conditioned freezing. . Neuroscience, 169 1501-1510.

Plendl W, Wotjak CT (2010). Dissociation of within- and between-session extinction of conditioned fear. J Neurosci, 30 4990-4998.

Rosas JM, Alonso G (1997). The effect of context change upon long-term memory of CS duration. Behav Processes, 39 69-76. 
Ruehle S, Rey AA, Remmers F, Lutz B (2012). The endocannabinoid system in anxiety, fear memory and habituation. J Psychopharmacol, 26 23-39.

Siegmund A, Wotjak CT (2007). A mouse model of posttraumatic stress disorder that distinguishes between conditioned and sensitised fear. J Psychiatr Res, 41 848-860.

Viveros MP, Marco EM, File SE (2005). Endocannabinoid system and stress and anxiety responses. Pharmacol Biochem Behav, 81 331-342. 
Table 1:

Precue lever-pressing and conditioned freezing in the rats tested for fear on days 2-3

\begin{tabular}{lccc}
\hline & \multicolumn{3}{c}{ Precue lever pressing (lever-press/min) } \\
& $\underline{0 \mathrm{mg} / \mathrm{kg}}$ & $\underline{1 \mathrm{mg} / \mathrm{kg}}$ & $\underline{3 \mathrm{mg} / \mathrm{kg}}$ \\
Day 2 test & $31.2 \pm 4.2$ & $26.4 \pm 3.0$ & $23.3 \pm 6.2$ \\
Day 3 retest & $30.0 \pm 4.5$ & $27.1 \pm 3.6$ & $22.2 \pm 4.1$ \\
& Precue conditioned freezing (\% freezing) \\
& $\underline{0 \mathrm{mg} / \mathrm{kg}}$ & $\underline{1 \mathrm{mg} / \mathrm{kg}}$ & $\underline{3 \mathrm{mg} / \mathrm{kg}}$ \\
Day 2 test & $1.7 \pm 1.0$ & $5.2 \pm 3.7$ & $5.5 \pm 3.4$ \\
Day 3 retest & $2.4 \pm 1.1$ & $6.0 \pm 3.2$ & $4.5 \pm 2.5$
\end{tabular}




\section{Figure legends}

Fig. 1. Experimental procedure: (A) Timeline of the fear incubation protocol design to study low, pre-incubated, fear. (B) Acquisition of lever pressing: total lever-presses during the 90 -min lever acquisition sessions ( $n=31)$. (C) Acquisition of fear conditioning: suppression ratios across 10 sessions of tone-shock pairings $(n=31) .{ }^{*}$ Different from Session $1, \mathrm{P}<0.05$.

Fig. 2. Conditioned fear was significantly higher after 1 month than 2-3 days after the end of extended fear conditioning (the fear incubation effect). (A) Conditioned suppression of lever-pressing. Mean ( \pm SEM) test suppression ratios in rats tested 30 min after vehicle injections 2 or 30 days after the end of fear conditioning and retested 24 hours later without injections. (B) Conditioned freezing. Mean ( \pm SEM) test conditioned freezing in rats in rats tested 30 min after vehicle injections 2 or 30 days after the end of fear conditioning and retested 24 hours later without injections. Left columns represent average behavior across each test session. Right columns represent trial-by-trial data across the 4 test trials in each test. $n=16,7-9$ per incubation day. ${ }^{*}$ Different from Day 2-3, $\mathrm{P}<0.05$.

Fig. 3. The low dose of SR141716 had no effect on fear expression, but impaired betweensession retention of conditioned fear extinction. (A) Conditioned suppression of lever-pressing. Mean $\left({ }_{ \pm}\right.$SEM) test suppression ratios in rats tested 30 min after SR141716 injections $(0,1$ or 3 $\mathrm{mg} / \mathrm{kg}$, s.c) and retested 24 hours later without SR141716 injections. (B) Conditioned freezing. Mean $( \pm$ SEM) test conditioned freezing in rats tested 30 min after SR141716 injections $(0,1$ or $3 \mathrm{mg} / \mathrm{kg}$, s.c) and retested 24 hours later without SR141716 injections. Left columns represent average behavior across each test session. Right columns represent trial-by-trial data across the 4 test trials in each test. $n=22,7-8$ per dose. * Different from the corresponding test in the 0 mg/kg group, $\mathrm{P}<0.05$. 


\section{A: Experimental procedure}

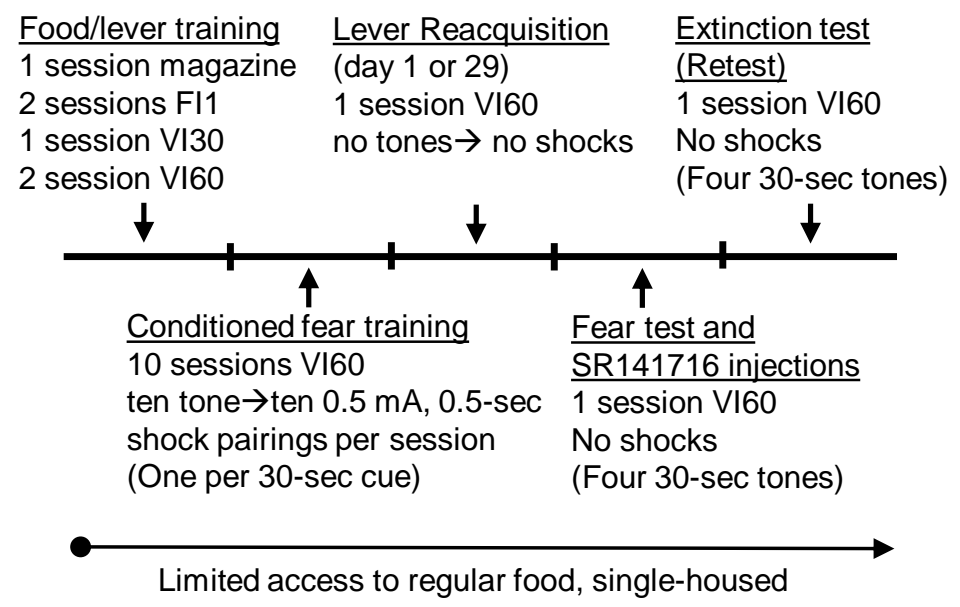

\section{B: Lever press training}

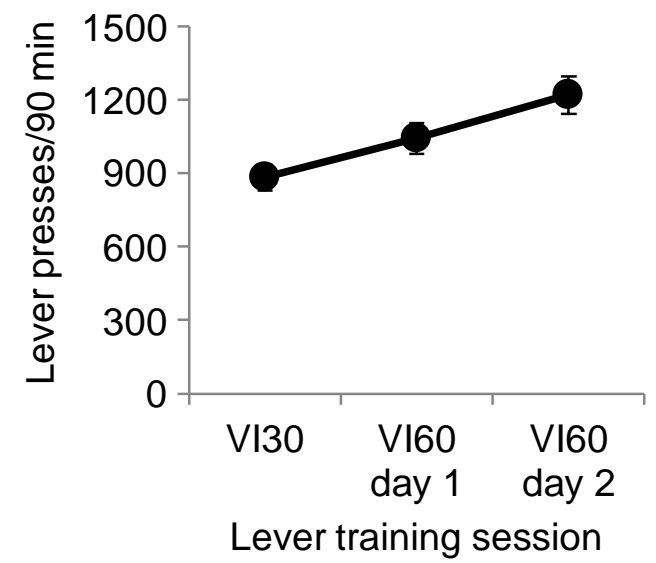

\section{C: Fear conditioning training}

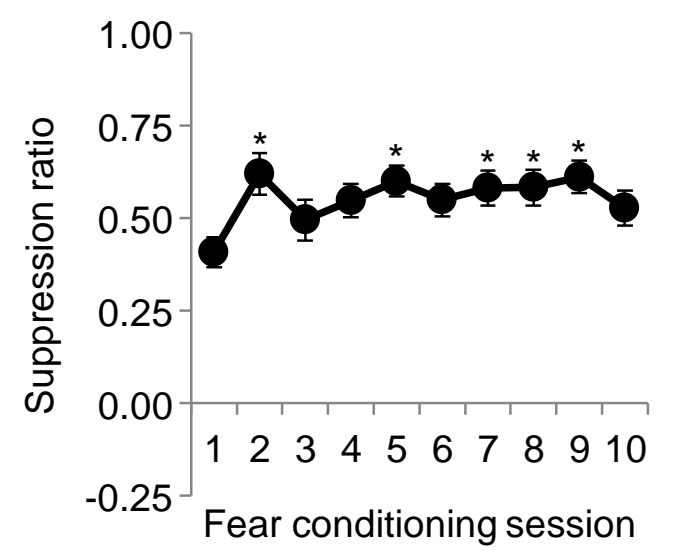


A: Conditioned suppression of lever pressing

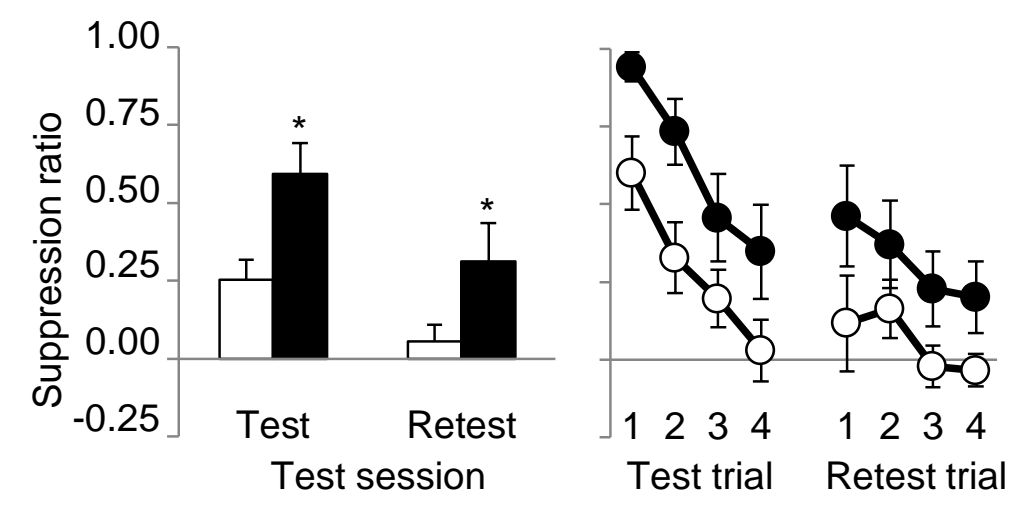

B: Conditioned freezing

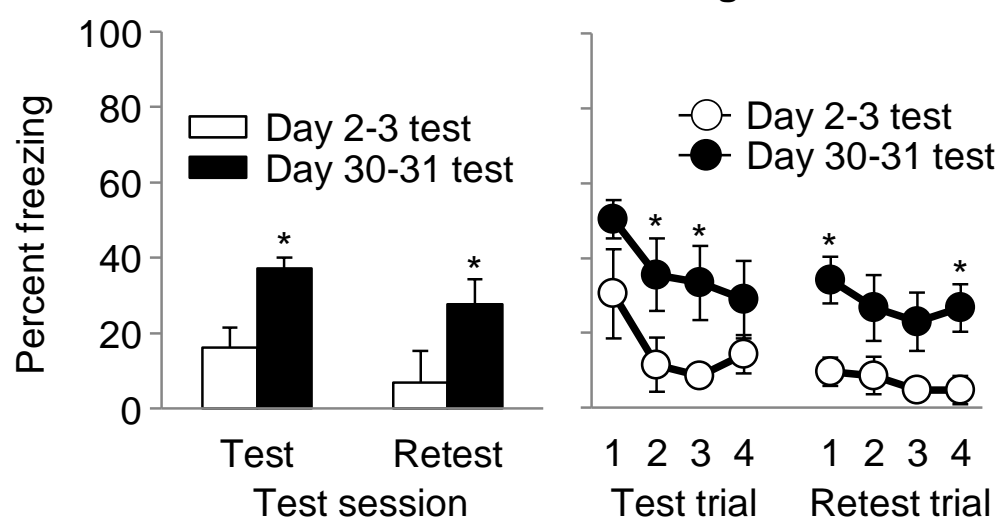

Figure 2 
A: Conditioned suppression of lever pressing
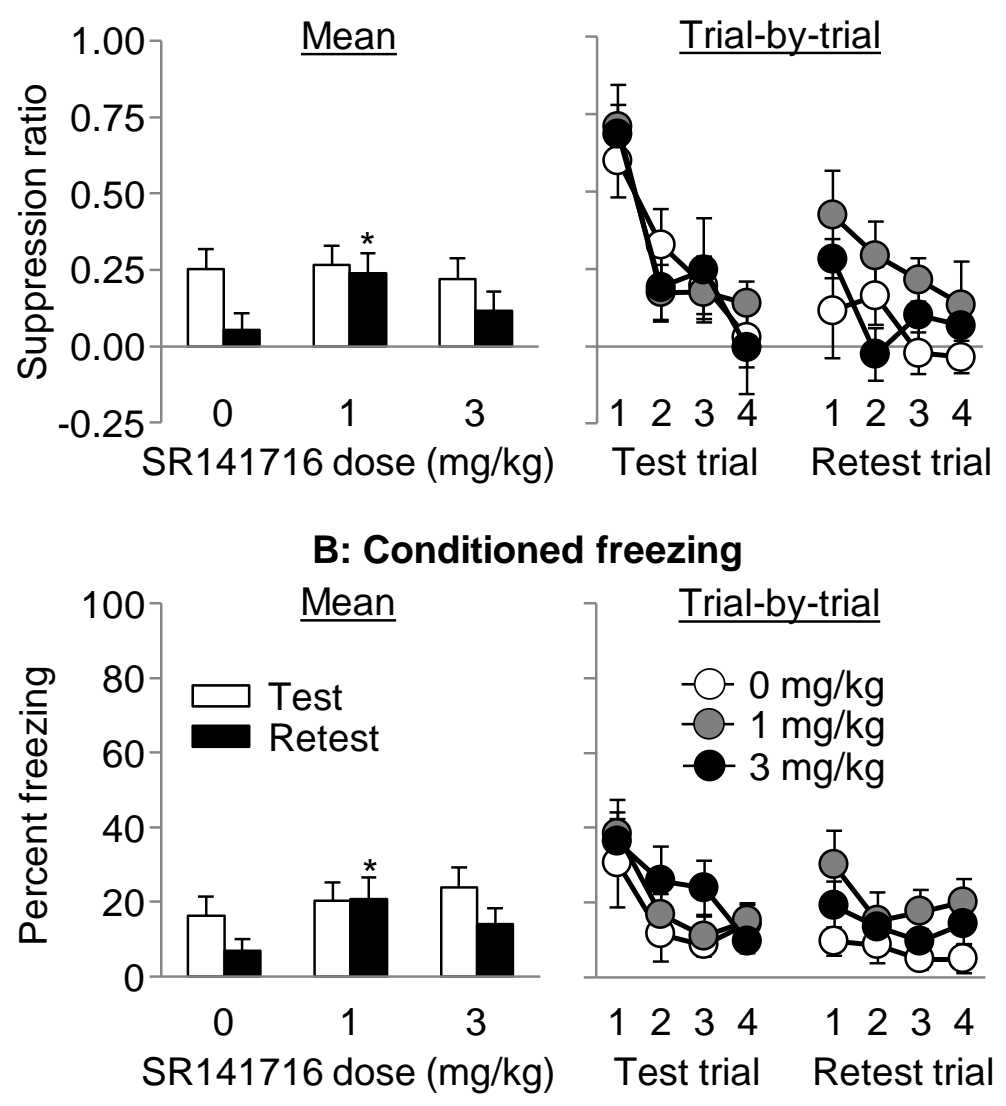

Figure 3 